\title{
VETSA: The Vietnam Era Twin Study of Aging
}

\author{
William S. Kremen ${ }^{1,2}$, Carol E. Franz ${ }^{1}$, and Michael J. Lyons ${ }^{2}$ \\ ${ }^{1}$ Department of Psychiatry and Center for Behavioral Genomics Twin Research Laboratory, \\ University of California, San Diego, CA, USA \\ ${ }^{2}$ Center of Excellence for Stress and Mental Health, VA San Diego Healthcare System, La Jolla, \\ CA, USA \\ ${ }^{3}$ Department of Psychology, Boston University, Boston, MA, USA
}

\begin{abstract}
The Vietnam Era Twin Study of Aging (VETSA) is a longitudinal behavioral genetic study with a primary focus on cognitive and brain aging in men. It comprises a subset of over 1,200 twins from the Vietnam Era Twin Registry. Like many other studies of aging, the VETSA includes many different phenotypes, but there are some key features that distinguish it from most other behavioral genetic aging studies. First, the initial assessment was conducted when all participants were middle-aged. Second, the age range of participants is narrow; all were in their 50s at the time of the initial recruitment. Third, the study includes an extensive and demanding neurocognitive test battery that was designed to provide good coverage of different cognitive abilities and avoid ceiling effects in middle-aged adults. Fourth, young adult cognitive test data (at an average age of 20 years) are available to provide a gauge of cognitive change. These features make the VETSA ideal for studying the heterogeneity of within-individual trajectories from midlife to old age, and for early detection of risk factors for cognitive decline.
\end{abstract}

\section{Keywords}

twins; aging; longitudinal; cognition; heritability

\section{Introduction}

The Vietnam Era Twin Study of Aging (VETSA) is a longitudinal behavioral genetic study focusing on cognitive and brain aging. An initial description of the VETSA projects (before completion of the first wave of data collection) appeared in the 2006 issue of Twin Research and Human Genetics (Kremen et al., 2006). Since that time, wave 1 data collection was completed and wave 2 is nearly complete as of the time of this writing. Participants were, on average, 55 and 60 years of age at wave 1 and wave 2, respectively. VETSA participants are all part of the larger Vietnam Era Twin Registry, which is also described in this issue. VETSA twins were randomly selected from a large prior study that attempted to enroll all available Registry twins (Tsuang et al., 2001). There were only two selection criteria for the VETSA: twins had to be in their 50s at the time of recruitment and both twins in a pair had to bewilling to participate in wave 1 .

(C) The Authors 2012

ADDRESS FOR CORRESPONDENCE: William S. Kremen, PhD, Department of Psychiatry, University of California, San Diego, La Jolla, CA 92093-0738.wkremen@ucsd.edu. 
This ascertainment strategy served three main purposes. First, it provided a baseline assessment in late midlife. Many important age-related changes begin at around ages 60-65. For example, lifetime risk for Alzheimer's disease increases substantially after age 65 (Sperling et al., 2011). Thus, for most participants, it will be possible to see changes before and after key aging-related transition points. As noted below, rates of several medical conditions that may be associated with cognitive aging increased significantly in the 5-year interval between VETSA wave 1 and wave 2 . Of course, age-related cognitive decline may have already taken place before the initial VETSA assessment, but aging studies that focus primarily on adults who are 60-65 or older at the initial assessment run a greater risk of observing baseline performance that already reflects meaningful decline from prior levels of functioning.

Second, the ascertainment strategy maximizes the ability to examine the heterogeneity of within-individual change. Within-individual change can only be studied with a longitudinal design, and change may differ from one age to another. By having an age-homogeneous sample, the VETSA design increases the feasibility of detecting differences in trajectories of change over time in people of essentially the same age. In particular, a large sample with a narrow age range should improve our ability to detect subgroups with different aging trajectories. Group mean cognitive change is likely to be small or absent in this age range, but there is growing evidence that some individuals do begin to manifest significant cognitive decline during midlife or in the transition from midlife to early old age (e.g., Singh-Manoux et al., 2011).

Third, the ascertainment strategy is useful for early identification of individuals who may be at elevated risk for developing mild cognitive impairment (MCI) or dementia later in life. Those individuals who are beginning to show evidence of decline from wave 1 to wave 2 may be at heightened risk for MCI or dementia. Indeed, although participants were only in their 50s at wave 1, a series of analyses is beginning to indicate that a proportion of them can be identified as already meeting criteria for MCI based on neuropsychological definitions. If these classifications are validated in follow-up assessments, it would suggest the possibility of detection much earlier than in prior studies. Related to this third purpose, general cognitive ability scores are available for VETSA participants when they were, on average, 20 years of age. The same cognitive test was readministered to VETSA participants during wave 1 of the study approximately 35 years later. It had excellent stability, with a phenotypic correlation of 0.74 over this lengthy interval (Lyons et al., 2009). Moreover, the genetic correlation was not significantly different from 1.0, indicating that the same genes were influencing individual differences in overall cognitive ability at both ages. As such, this test is also useful as a gauge of how much cognitive performance may have changed from early adult functioning even at the first wave of the study.

\section{VETSA Sample}

Data collection for VETSA wave 1was conducted from 2003 to 2007. A total of 1,237 twins participated (349 monozygotic pairs, 265 dizygotic pairs, and 9 unpaired). As of August 2012, over 1,000 twins have participated in wave 2, the project's first 5-year follow-up. There are also attrition-replacement participants who comprise a subset of the wave 2 participants. Attrition-replacement participants are twin pairs from the Vietnam Era Twin Registry in the same age range as the returning wave 2 participants, but the attritionreplacement participants underwent the assessments for the first time. Therefore, these individuals serve as a direct gauge for practice effects on cognitive tests. Given evidence in other studies of practice effects even after a 5-year interval (Rönnlund et al., 2005), the attrition-replacement participants serve an important function of disentangling aging and 
practice effects. The vast majority of tests and questionnaires were administered at both times.

All VETSA participants are men and all were in some branch of military service at some time between 1965 and 1975. The majority were not in combat or in Vietnam. At the time of the study, they were a reasonably representative, community-dwelling sample of middleaged men living throughout the entire United States based on their comparability to American men in their age range with respect to socio-demographic and health characteristics (Schoeneborn \& Heyman, 2009). In addition to the study of cognitive and brain aging, the VETSA is also well suited to the study of numerous other aspects of male aging. Examples include the impact on cognition of testosterone level and testosterone decline, and microvascular disease as exemplified by erectile dysfunction.

\section{VETSA Measures}

With the primary focus of the VETSA on cognitive aging, the project includes an extensive neurocognitive test battery. Because it is also important to understand how other factors affect or may be affected by level of cognitive functioning, there are detailed assessments of personality and psychosocial/lifestyle measures as well as biomedical measures. The neurocognitive battery was designed to increase coverage of cognitive functions that had not received much emphasis in behavioral genetic studies of middle-aged and older adults. Different key processes have been posited in different theories as the major factors underlying cognitive change in middle age and older adulthood. These include general processing speed (Salthouse, 1996), declines in the capacity of working memory (Hultsch et al., 1998; Salthouse, 1991; Wingfield et al., 1988), reduced efficiency in inhibiting off-target thoughts and stimuli (Hasher \& Zacks, 1988; Zacks et al., 2000), declining effectiveness in learning and retrieval from episodic memory (Kausler, 1994), and inefficiency in the ability to process context information (i.e., internally represented information used to influence planning and behavior; Braver et al., 2002). Processing speed and episodic memory have been included in previous behavior genetic studies of aging, but these other cognitive functions have received little attention. The VETSA neurocognitive battery was also designed to avoid ceiling effects in middle-aged adults. Otherwise, ceiling effects can greatly reduce the ability to observe heterogeneity of trajectories.

\section{Magnetic Resonance Imaging (MRI)}

A companion VETSA project includes the administration of MRIs to a subset of participants. At VETSA 1, 526 twins underwent 3D structural MRIs to measure brain structure (cortical and subcortical volumes and cortical thickness and surface area). In conjunction with the VETSA 2 follow-up, these twins are also undergoing a second MRI. In the follow-up protocol, participants also undergo a functional MRI protocol to assess the default mode network. The default mode network is active when individuals are left to think to themselves undisturbed, and it tends to deactivate when individuals are engaged in a cognitive task (Buckner et al., 2008). Default network activity is relevant because crosssectional results suggest that activity correlation between regions in this network tend to decrease with age, and those correlations may be reduced further in Alzheimer's disease as compared with normal aging (Buckner et al., 2008; Greicius et al., 2004). Participants also undergo an arterial spin labeling protocol to provide an index of resting regional cerebral blood flow or perfusion. This measure may be important for understanding cognitive and brain aging because there are age-related changes in perfusion and they may reflect important vascular changes (Beason-Held et al., 2008; D’Esposito et al., 2003).

VETSA MRI data have been used to show the heritability of the size of individual cortical and subcortical regions of interest (Eyler et al., 2011; Kremen, Prom-Wormley et al., 2010), 
the genetic associations among continuously measured cortical regions (Chen et al., 2011; Eyler et al., 2012; Rimol et al., 2010), and the genetic distinction between cortical thickness and cortical surface area (Panizzon et al., 2009). In addition, they have been used to create a novel brain atlas of cortical regions defined entirely on the basis of genetically informative data (Chen et al., 2012). This atlas may be useful for genetic association studies because the brain phenotypes are defined by genetic rather than structural or functional information.

\section{Neuroendocrine Data}

In another companion project that was linked only to wave 1 of the VETSA, neuroendocrine data from saliva samples were collected from 795 VETSA participants. A total of 17 samples per person were collected: 5 on each of two days at home and 7 on the in-lab day. The schedule for sampling was designed primarily for the assessment of the stress hormone cortisol. Cortisol follows a diurnal variation in which the peak is typically shortly after awakening and levels then decline throughout the day. Samples were thus collected at awakening, 30 minutes after awakening, 10 hours, 15 hours, and bedtime. Two additional samples were collected just before and just after lunch on the day of testing. In addition to cortisol, the saliva samples were also used to measure testosterone and dehydroepiandrosterone sulfate (DHEA-S). Because cortisol is important in the hypothalamic-pituitary-adrenal axis stress response system, it may be a mediator or moderator of age-related changes. Testosterone and DHEA-S may have opposing effects to that of cortisol. Moreover, because testosterone levels decline steadily with age, testosterone changes may be another important factor in male aging. Studies based on VETSA data have shown the heritability of these hormones (Franz et al., 2010; Prom-Wormley et al., 2011) and their relationship to cognition and brain (Franz et al., 2011; Kremen, O’Brien et al., 2010; Panizzon et al., 2010, 2012).

\section{Summary}

The VETSA projects include comprehensive assessments of twins in multiple domains beginning in the sixth decade of life. At the time of this writing, they are being studied in the first of several planned follow-up assessments. The current plan is to reassess every 5 years, but it may become important to shorten the time interval as the participants get older. As such, we hope that the ongoing VETSA projects will provide a valuable resource for the study of genetic and environmental influences on cognitive and brain aging. It is also worth noting that although cognition and brain are the major areas of emphasis in the VETSA projects, there are ample data to explore many other important aspects of the aging process. In addition, the VETSA is already serving as a scientific resource as part of the consortium on Interplay of Genes and Environment across Multiple Studies (IGEMS; this issue).

\section{References}

Beason-Held LL, Kraut MA, Resnick SM. I. Longitudinal changes in aging brain function. Neurobiology of Aging. 2008; 29:483-496. [PubMed: 17184881]

Braver, TS.; Cohen, JD.; Barch, DM. The role of prefrontal cortex in normal and disordered cognitive control: A cognitive neuroscience perspective. In: Stuss, DT.; Knight, RT., editors. Principles of Frontal Lobe Function. Oxford: Oxford University Press; 2002. p. 428-448.

Buckner RL, Andrews-Hanna JR, Schacter DL. The brain's default network: Anatomy, function, and relevance to disease. Annals of the New York Academy of Sciences. 2008; 1124:1-38. [PubMed: 18400922]

Chen CH, Gutierrez ED, Thompson W, Panizzon MS, Jernigan TL, Eyler LT, Dale AM. Hierarchical genetic organization of human cortical surface area. Science. 2012; 335:1634-1636. [PubMed: 22461613] 
Chen CH, Panizzon MS, Eyler LT, Jernigan TL, Thompson W, Fennema-Notestine C, Dale AM. Genetic influences on cortical regionalization in the human brain. Neuron. 2011; 72:537-544. [PubMed: 22099457]

D'Esposito M, Deouell LY, Gazzaley A. Alterations in the BOLD fMRI signal with ageing and disease: A challenge for neuroimaging. Nature Reviews Neuroscience. 2003; 4:863-872.

Eyler LT, Chen CH, Panizzon MS, Fennema-Notestine C, Neale MC, Jak A, Kremen WS. A comparison of heritability maps of cortical surface area and thickness and the influence of adjustment for whole brain measures: A magnetic resonance imaging twin study. Twin Research and Human Genetics. 2012; 15:304-314. [PubMed: 22856366]

Eyler LT, Prom-Wormley E, Panizzon MS, Kaup AR, Fennema-Notestine C, Neale MC, Kremen WS. Genetic and environmental contributions to regional cortical surface area in humans: A magnetic resonance imaging twin study. Cerebral Cortex. 2011; 21:2313-2321. [PubMed: 21378112]

Franz CE, O’Brien RC, Hauger RL, Mendoza SP, Panizzon MS, Prom-Wormley E, Kremen WS. Cross-sectional and 35-year longitudinal assessment of salivary cortisol and cognitive functioning: The Vietnam Era twin study of aging. Psychoneuroendocrinology. 2011; 36:1040-1052. [PubMed: 21295410]

Franz CE, York TP, Eaves LJ, Mendoza SP, Hauger RL, Hellhammer DH, Kremen WS. Genetic and environmental influences on cortisol regulation across days and contexts in middle-aged men. Behavior Genetics. 2010; 40:467-479. [PubMed: 20238238]

Greicius MD, Srivastava G, Reiss AL, Menon V. Default-mode network activity distinguishes Alzheimer's disease from healthy aging: Evidence from functional MRI. Proceedings of the National Academy of Sciences U S A. 2004; 101:4637-4642.

Hasher, L.; Zacks, RT. Working memory, comprehension, and aging: A review and new view. In: Bower, GH., editor. The Psychology of Learning and Motivation: Vol. 22. New York: Academic Press; 1988. p. 193-225.

Hultsch, DF.; Hertzog, C.; Dixon, RA.; Small, BJ. Memory Change in the Aged. Cambridge: Cambridge University Press; 1998.

Kausler, DM. Learning and Memory in Normal Aging. San Diego, CA: Academic Press; 1994.

Kremen WS, O’Brien RC, Panizzon MS, Prom-Wormley E, Eaves LJ, Eisen SA, Franz CE. Salivary cortisol and prefrontal cortical thickness in middle-aged men: A twin study. Neuroimage. 2010; 53:1093-1102. [PubMed: 20156572]

Kremen WS, Prom-Wormley E, Panizzon MS, Eyler LT, Fischl B, Neale MC, Fennema-Notestine C. Genetic and environmental influences on the size of specific brain regions in midlife: The VETSA MRI study. Neuroimage. 2010; 49:1213-1223. [PubMed: 19786105]

Kremen WS, Thompson-Brenner H, Leung YJ, Grant MD, Franz CE, Eisen SA, Lyons MJ. Genes, environment, and time: The Vietnam Era Twin Study of Aging (VETSA). Twin Research and Human Genetics. 2006; 9:1009-1022. [PubMed: 17254445]

Lyons MJ, York TP, Franz CE, Grant MD, Eaves LJ, Jacobson KC, Kremen WS. Genes determine stability and the environment determines change in cognitive ability during 35 years of adulthood. Psychological Science. 2009; 20:1146-1152. [PubMed: 19686293]

Panizzon MS, Fennema-Notestine C, Eyler LT, Jernigan TL, Prom-Wormley E, Neale MC, Kremen WS. Distinct genetic influences on cortical surface area and cortical thickness. Cerebral Cortex. 2009; 19:2728-2735. [PubMed: 19299253]

Panizzon MS, Hauger R, Dale AM, Eaves LJ, Eyler LT, Fischl B, Kremen WS. Testosterone modifies the effect of APOE genotype on hippocampal volume in middle-aged men. Neurology. 2010; 75:874-880. [PubMed: 20819998]

Panizzon MS, Hauger RL, Eaves LJ, Chen CH, Dale AM, Eyler LT, Kremen WS. Genetic influences on hippocampal volume differ as a function of testosterone level in middle-aged men. Neuroimage. 2012; 59:1123-1131. [PubMed: 21983185]

Prom-Wormley EC, York TP, Jacobson KC, Eaves LJ, Mendoza SP, Hellhammer D, Kremen WS. Genetic and environmental effects on diurnal dehydroepiandrosterone sulfate concentrations in middle-aged men. Psychoneuroendocrinology. 2011; 36:1441-1452. [PubMed: 21570195] 
Rimol LM, Panizzon MS, Fennema-Notestine C, Eyler LT, Fischl B, Franz CE, Dale AM. Cortical thickness is influenced by regionally-specific genetic factors. Biological Psychiatry. 2010; 67:493499. [PubMed: 19963208]

Rönnlund M, Nyberg L, Backman L, Nilsson LG. Stability, growth, and decline in adult life span development of declarative memory: Cross-sectional and longitudinal data from a populationbased study. Psychology and Aging. 2005; 20:3-18. [PubMed: 15769210]

Salthouse TA. Mediation of adult age differences in cognition by reductions in working memory and speed of processing. Psychological Science. 1991; 2:179-183.

Salthouse TA. The processing-speed theory of adult age differences in cognition. Psychological Review. 1996; 103:403-428. [PubMed: 8759042]

Schoeneborn, CA.; Heyman, KM. Health characteristics of adults aged 55 years and over: United States, 2004-2007. Hyattsville, MD: National Center for Health Statistics; 2009.

Singh-Manoux A, Kivimaki M, Glymour MM, Elbaz A, Berr C, Ebmeier KP, Dugravot A. Timing of onset of cognitive decline: Results from Whitehall II prospective cohort study. BMJ. 2011; 343:d7622. [PubMed: 22223828]

Sperling RA, Aisen PS, Beckett LA, Bennett DA, Craft S, Fagan AM, Phelps CH. Toward defining the preclinical stages of Alzheimer's disease: Recommendations from the National Institute on AgingAlzheimer's Association workgroups on diagnostic guidelines for Alzheimer's disease. Alzheimer's and Dementia. 2011; 7:280-292.

Tsuang MT, Bar JL, Harley RM, Lyons MJ. The Harvard Twin Study of Substance Abuse: What we have learned. Harvard Review of Psychiatry. 2001; 9:267-279. [PubMed: 11600486]

Wingfield A, Stine EAL, Lahar CJ, Aberdeen JS. Does the capacity of working memory change with age? Experimental Aging Research. 1988; 14:103-107. [PubMed: 3234452]

Zacks, RT.; Hasher, L.; Li, KZH. Human memory. In: Craik, FIM.; Salthouse, TA., editors. Handbook of Aging and Cognition. 2nd ed.. Mahwah, NJ: Erlbaum; 2000. p. 293-357. 